\title{
IoT-Based Automated Garden Irrigation and Monitoring System Using Advanced Technology
}

\author{
${ }^{1}$ Mohamad Simpal, ${ }^{2}$ Aldrin Jurao, Jr., ${ }^{3}$ Cydrick John Estrella, ${ }^{4}$ Karyl June Jardiolin, ${ }^{5}$ Trishia Claire Leyza \\ ${ }^{1}$ Master Teacher I, Department of Education, Esperanza National High School, Philippines \\ ${ }^{2,3,4,5}$ Researcher, Department of Education, Esperanza National High School, Philippines
}

\begin{abstract}
With the successful use of the Internet of Things (IoT) in the field of agriculture, particularly in small gardening, all elements of farming can be automated, making the process more efficient and productive. This project sought to create a highly dependable and practical IoT-based Automated Garden Irrigation and Monitoring system. This project also aims to provide an application for the systems to monitor the environment, soil, and garden plants properly. This project utilized eleven hardware components, including an ESP8266 Wi-Fi module, an ESP8266 Expansion Base Board, an Arduino Uno, a temperature and humidity sensor, a soil moisture sensor, an ultrasonic sensor, a servo motor, a relay, jumper wires, and a breadboard. The project utilizes ESP8266 and Arduino Uno as the sensors' central processing units. The application allowed users to monitor the environment's temperature, humidity, and soil moisture. The software also enables users to control the project's irrigation system and monitor the water pump's operation. The project and application were linked to a Google Firebase real-time database to receive and deliver data from the components to the application. Thus, the finding was revealed to be highly reliable, practical, and relevant for modern gardening.
\end{abstract}

Keywords: Advanced Technology, Automated, Garden Irrigation, Monitoring System.

\section{INTRODUCTION}

Every day, the world's issues create new technology to solve them. Urban agriculture is one of them. It can help a family's food security. It promotes the local economy and thus the social and economic well-being of that particular resident. It also reduces carbon emissions by reducing food, vegetable, and fruit transportation from other regions or nations. It also frees up farm and for natural regrowth. Urban agriculture requires a lot of dedication because there are commitments and hurdles to overcome. This encompasses both the garden and the plants. Maintenance can be difficult, especially in cities where most people are busy, leading to garden neglect and plant wilting [1].
Urban gardens benefit the environment and hence the socioeconomic situations, allowing for diverse resources to spot better crop control approaches. In this respect, investigations have been done on soil physical features such as infiltration rate to improve water distribution and consumption [2] texture and density, for agricultural planning and decision making [3]; and soil quality, to ensure that harvested crops are free of pollutants and fit for human consumption. These monitoring and irrigation systems can now be connected to the Internet of Things (IoT) for user access and engagement and to optimize water use and irrigation. Object identification and knowledge compilation, conveying information, information management applications, and intelligent services are the four levels of these systems [4].

It can be the reason why the Internet of Things (IoT) is a game-changer with globally networked things backed by standard communication protocols [5]. It's a network of interconnected devices that can collect and transfer data wirelessly without human intervention. The Internet of Things (IoT) is a future Internet component of global data and webconnected items. IoT reduces human involvement by automating processes. Automation takes data via sensors, processes it via controllers, and completes the process with actuators [6]-[7]. Many studies discuss robotics in urban gardening simple Arduino Smart Home Monitoring System for Effective Gardening [1]. The idea attempted to create a machine that could constantly monitor the garden. The project can develop an automated monitoring system that can simultaneously analyze the acidity of the garden's water, soil moisture, and temperature. It also helps regulate the garden's watering system by turning the water pump that draws water from the reservoir. Soil acidity, temperature, and moisture are monitored.

Another project made which can monitor and regulate a system that measures the greenhouse's temperature, humidity, and soil moisture. It employed GSM Module for user-robot interaction. It used an Arduino Uno as the central processor unit and analog sensors to determine the design parameters [8].The design incorporates a decision-making system for intelligent irrigation that conserves water. The proposed method improves crop quality while preserving the 
ISSN (online): 2581-3048

environment. The idea also reduces human intervention at night [9].IoT converts agriculture and food into intelligent webs of connected things that can be identified, sensed, and controlled remotely. It is likely to change agri-food processes, resulting in new control mechanisms and commercial models [10].

The Internet of Things can help inform the plant's state so that if more action is required, like watering, it can be done immediately. This study used an ESP8266 microcontroller and a Wi-Fi link to the internet, allowing the sensor data to be sent directly on the internet. Weather, soil moisture, air humidity, and light sensors are put on plants and sent to the web app via REST API [11].Agricultural robotics minimized human involvement while boosting efficiency. Because agriculture is vital to any country's economy, water and land users should maximize their resources [12].Sensors collect extensive data on the agricultural environment via IoT. It identifies and interacts with big data models to make agriculture more sustainable [13]. The Internet of Things (IoT) can collect data efficiently and affordably. It's a game of chess. The Internet of Things will help agriculture. Water is vital in agriculture [14]. Farmers rely on rain for all their needs.

Fertilizer is also used in agriculture to boost plant productivity [15]. Farmers can monitor soil conditions more efficiently and cost-effectively using IoT and other technologies employed in agriculture to conserve water, fertilizer, and energy to benefit a country's economy and its residents [16]. Using modern hardware and software technologies, IoT can track and count every phase of production, decreasing waste, loss, and costs. Electronic gadgets can offer all necessary information [15]. IoT improves agriculture and helps farmers overcome problems. Innovative solutions can enhance the quality of the crop, quantity, sustainability, and cost-effectiveness [17]. In emerging countries like India, agriculture is one of the primary resources for revenue, which has a large geographical region [18].

Most water management research has been done by monitoring environmental indicators, including temperature, humidity, and soil moisture. Many findings focused on greater water utilization, less human intervention, and lower production costs [19]. Since waste management, smart lighting, and pest control have gotten the least research attention in the considered period, future studies could focus on further automating present procedures. There are limitations to IoT in agriculture and farming. Future studies should address device interoperability, and compatibility, network flexibility challenges as additional devices connect, and sensor lifetime.

\subsection{Objectives of the Project}

This project generally aimed to create an IoT-based Automated Garden Irrigation and Monitoring System Using Advanced Technology that is highly reliable and useful for modern gardening.

Specifically, this project aimed to:

1. construct a prototype of an IoT-based Automated Garden Irrigation and Monitoring System using Advanced Technology

2. design and create an application for the IoT-based Automated Garden Irrigation and Monitoring using Advanced Technology through the development of the following software applications:

a. Google Firebase

b. MIT App Inventor

Readings and functionality tests of the prototype designed through the use of the following sensors:
a. Temperature and Humidity Sensor
b. Soil moisture Sensor
c. Ultrasonic Sensor

\subsection{Conceptual Design}

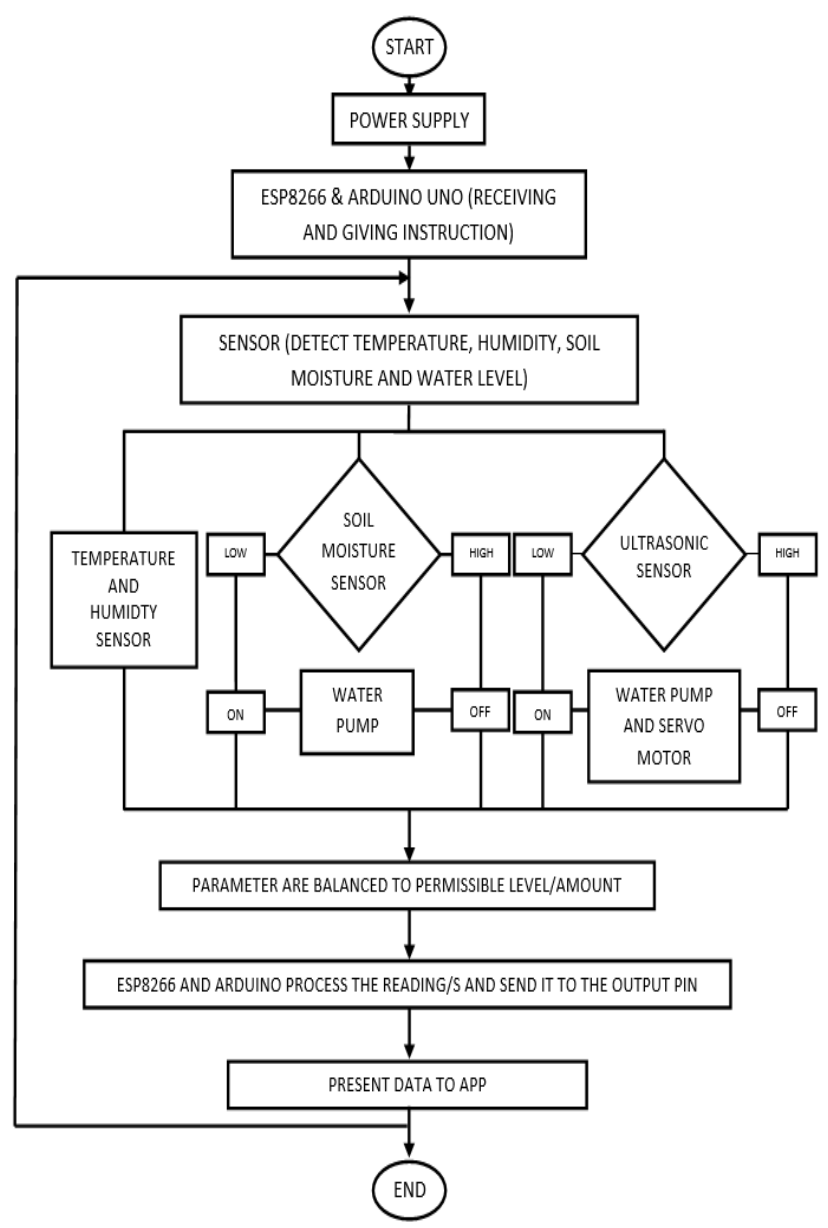

Figure 1: Conceptual Design of the Project 


\section{MATERIALS AND METHODS}

Here you will find the materials, system design of the Project, project's block diagram, and statistical analysis used.

\subsection{Materials}

The hardware components utilized in this project included an ESP8266 Wi-Fi module and an ESP8266 expansion-based board for web-based data transmission. While a temperature and humidity sensor and a soil moisture sensor were utilized to monitor soil moisture and temperature readings, respectively. An ultrasonic sensor connected to a relay module was utilized to operate the water pump for water resources and the servo motor for pouring out the fertilizer to be mixed in the water reservoir. Additionally, jumper wires, a breadboard, and the project's central processing unit, such as an Arduino uno, were utilized.

\subsection{System Design of the Project}

The IoT-based Automated Garden Irrigation and Monitoring System builds on previous research done by the same researcher. It requires three (3) sensors: soil moisture sensor, temperature and humidity sensor, and ultrasonic sensor for irrigation. Components include ESP8266 Wi-Fi Module, ESP8266 Expansion Base Board, Arduino Uno, Temperature and Humidity sensor, Soil moisture sensor, Ultrasonic sensor, Servo motor, Relay and Water pump. The ESP8266 Wi-Fi Module is the system's brain, controlling the process and connecting it to the wireless network. In response to the sensors' detection of a change in the environment, the ESP8266 Wi-Fi Module takes action. Whenever the environment changes, the system processes the data and updates the user via a Wi-Fi connection to an app.

The user utilized the app to command the machine depending on the state. An app button controls the relays to regulate the watering system. The Analog pin temperature and humidity sensor measures the garden's temperature and humidity. The garden's soil wetness is measured using a soil moisture sensor attached to an Analog pin. The ultrasonic sensor attached to an Analog pin measures the reservoir's water level. The servo motor opens a seal in the water reservoir allowing the fertilizer to be combined. The system uses two (2) water pumps, each coupled to one (1) relay, the first pump supplying water to the water reservoir, and the second supplying fertilizer-laced water to the garden.

The DHT library reads the humidity and temperature sensor (DHT11 basic) and sends the data to the user through Wi-Fi. As well as monitoring and controlling the system.
https://doi.org/10.47001/IRJIET/2021.511008

\subsection{Block diagram}

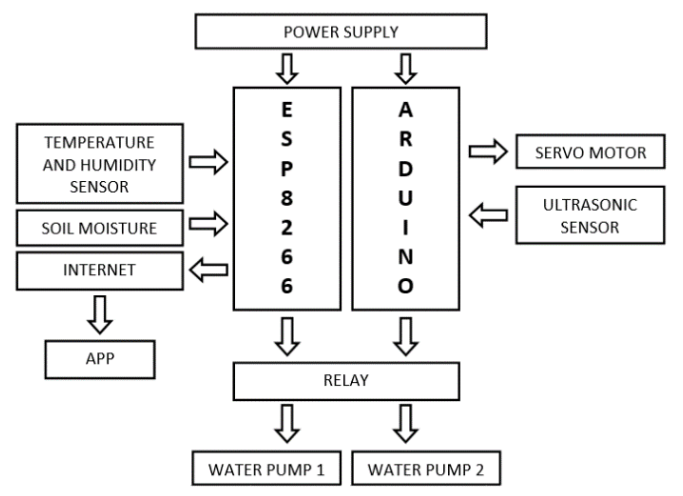

Figure 2: Block diagram of the project

\subsection{Statistical Analysis}

To collect the data required for the project, a series of experimental tests were conducted to validate the design's accuracy and reliability. To analyze and interpret the experiment's outcomes, descriptive statistics were used. Frequency and mean were used to assess and analyze data acquired from a series of experiments conducted by the researchers to determine the accuracy of the Firebase Database Application's connectivity sequence. The same sort of statistics was used in the construction of the project's mobile application, which was validated through a series of tests and trials. Finally, frequency, mean, and percentage were used to assess and interpret the findings from the series of temperature and humidity sensor tests and trials, as well as the accuracy of the ultrasonic sensor and soil moisture sensor.

\section{RESULTS AND DISCUSSIONS}

The hardware tests were performed to validate the reading and functionality of the sensors. This section describes how the product responds to data received and displays and informs users via the Application. The product has three analog sensors (temperature, humidity, and soil moisture) and one digital sensor (ultrasonic). These sensors feed the ESP8266 and Arduino Uno.

\subsection{Prototype design of the Project}

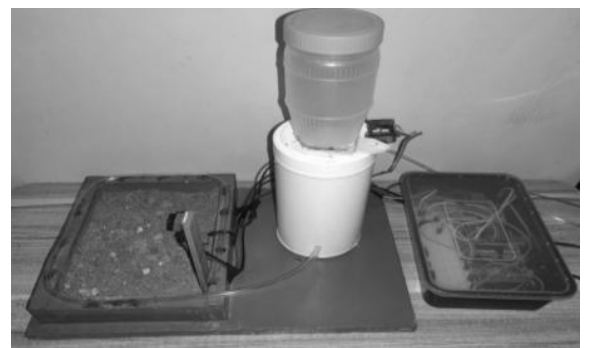

Figure 3: Prototype design 
ISSN (online): 2581-3048

As shown in Fig. 3, it is the Project's Actual Prototype. The ESP8266 board, Arduino Uno, two relays, and breadboard were all inside a black container to make connections more manageable and keep the prototype tidy. The project's irrigation system is positioned in the center, with the water reservoir, water pump, ultrasonic sensor, servomotor, and fertilizer container on top. It has a garden, a soil moisture sensor, a temperature and humidity sensor on top of it, and a hose connecting to the water reservoir below it. The entire prototype is controlled remotely using the researchers' developed applications.

3.2 Google Firebase Database Application and Real-time connections between the Prototype design and Google Firebase Database

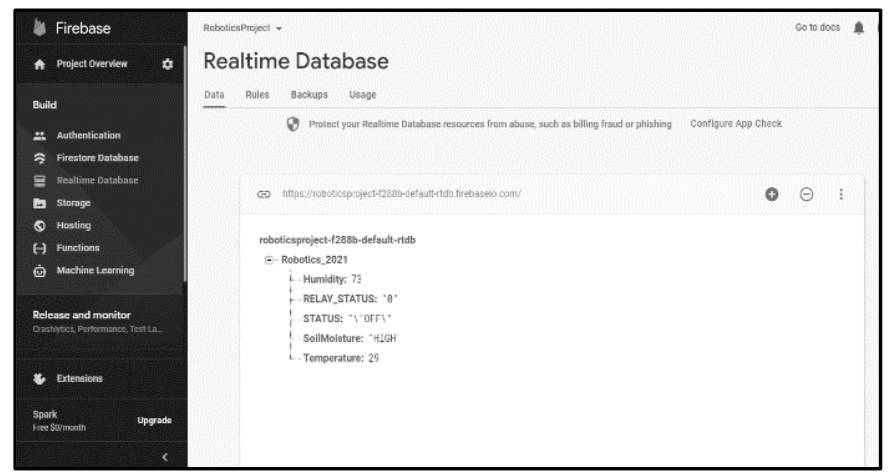

Figure 4: Firebase real-time database connection and reading

As demonstrated in Fig. 4, the Project's Real-time Database is vital for connecting the prototype and application. Google Firebase has a real-time database. A Google account generated for the project was used to access Google Firebase to create the project's database. The database key code connects the ESP8266 to the real-time database and allows data transmission and receiving. The real-time database contains sensor readings, sensor functionality, and water pump management and status. The ESP8266 automatically sends and changes the value to the real-time database when a sensor value changes. The RELAY STATUS in the real-time database for the project's irrigation system must be 1 to turn on the water pump and 0 to turn it off.

\begin{tabular}{|c|c|}
\hline $\begin{array}{l}\text { connected: Universe_101 } \\
192.168 \cdot 0.114 \\
\text { Current humidity }=70.008 \text { temperature }=29.00 \mathrm{C} \\
\text { soil moisture }=1024 \\
\text { Relay Turned OF? } \\
\text { Current humidity }=70.008 \text { temperature }=29.00 \mathrm{C} \\
\text { soil moisture }=1024 \\
\text { Relay Turned OF? }\end{array}$ & 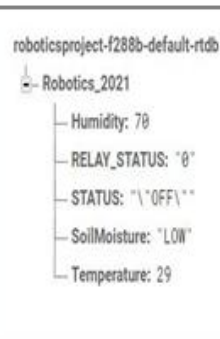 \\
\hline
\end{tabular}

Figure 5: The reading display on the serial monitor and Real-time Database
As illustrated in Fig. 5, the Serial Monitor displayed connected along with the Wi-Fi SSID and local IP address, indicating that the ESP8266 is connected to the user's Wi-Fi. The fact that the values of the sensors displayed in the Serial Monitor match the values in the Firebase real-time database demonstrates that the ESP8266 and the real-time database are connected and that data or commands can be received and delivered between them successfully.

\subsection{Mobile application, Prototype Design, and Google Firebase connections}

The project's mobile app is shown in Fig. 6. The picture to the right shows the Application Icon for the project title. A screenshot of the application was provided on the left side while the application was open. MIT App Inventor was used to create the mobile app. Components (texts, labels, buttons, etc.) and non-visible components (Firebase Database Component) were provided via MIT App Inventor. The database key code was utilized to link the mobile app to the real-time database. In the mobile app design, the project title is displayed at the top of the screen. The monitoring system for temperature, humidity, and soil moisture is in the screen's center. Sensor values are shown underneath the designated text. Two buttons also control the project's watering system in the middle of the board. The water pump status is shown to the left of it. This app requires an internet connection to work.
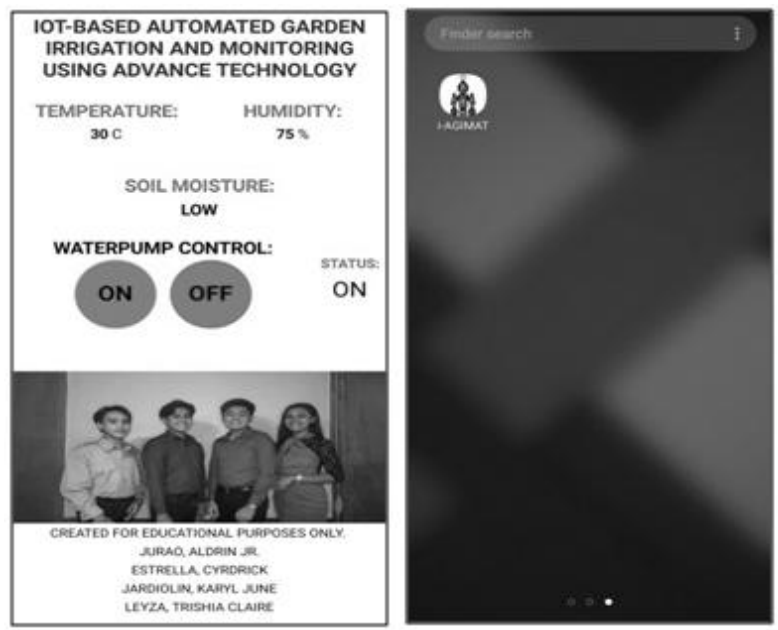

Figure 6: Mobile application developed for monitoring and controlling system

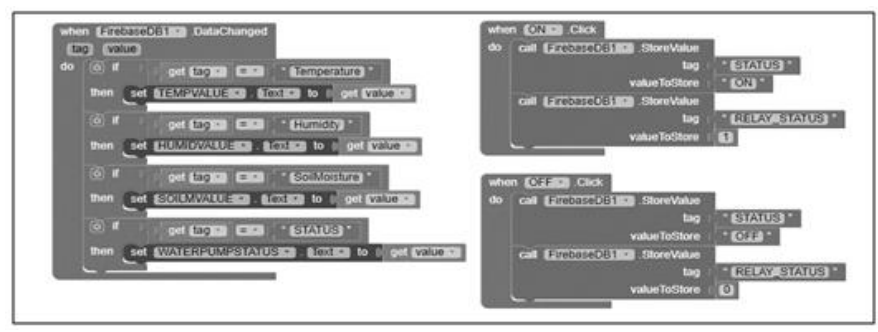

Figure 7: Block codes for the Mobile application 
ISSN (online): 2581-3048

Volume 5, Issue 11, pp 44-51, November-2021

https://doi.org/10.47001/IRJIET/2021.511008

Other than using Firebase Data Component named FirebaseDB1, block coding was made and encoded to the application to execute its functions, as shown in Fig.7. To the left is a list of codes for the monitoring system. The values in the Firebase real-time database were shown as text on the mobile app. The right blocks showed the codes for the mobile application's buttons for the project's irrigation system. The codes affected the value on the firebase real-time database when switched ON or OFF.

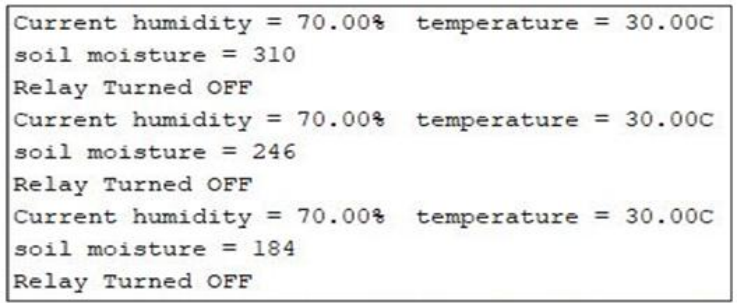

Figure 8: Readings presented on the serial monitor

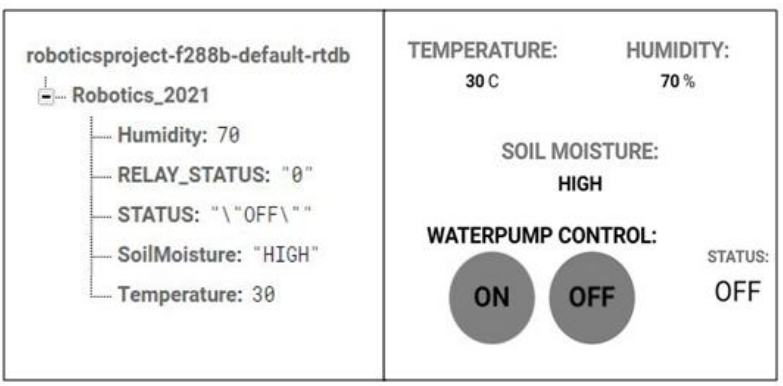

Figure 9: Reading display on the Mobile application and Firebase Realtime database

Google Firebase connects the Project Design and Mobile App. It is an online database that receives data from the Project Design and sends it to the Mobile Application. It also acted as the irrigation systems command center, receiving commands from the Mobile Application and transmitting them to the Project Design. As seen in Fig. 8 and Fig. 9, the Prototype Design, Google Firebase, and Mobile Application data were identical. It connected the Prototype Design, Google Firebase, and Mobile App. So, the Prototype Design and Mobile Application link worked.

\subsection{Readings and functionality test of the sensors}

Table 1: Temperature Sensor Reading

\begin{tabular}{|c|c|c|c|c|c|c|}
\hline $\begin{array}{c}\text { Condition/ } \\
\text { Substance }\end{array}$ & $\begin{array}{c}\text { Trial } \\
\mathbf{1}\end{array}$ & $\begin{array}{c}\text { Trial } \\
\mathbf{2}\end{array}$ & $\begin{array}{c}\text { Trial } \\
\mathbf{3}\end{array}$ & $\begin{array}{c}\text { Trial } \\
\mathbf{4}\end{array}$ & $\begin{array}{c}\text { Trial } \\
\mathbf{5}\end{array}$ & Mean \\
\hline $\begin{array}{c}\text { Cold Air } \\
\text { (Ice) }\end{array}$ & $13^{\circ} \mathrm{C}$ & $14^{\circ} \mathrm{C}$ & $13^{\circ} \mathrm{C}$ & $14^{\circ} \mathrm{C}$ & $14^{\circ} \mathrm{C}$ & $13^{\circ} \mathrm{C}$ \\
\hline $\begin{array}{c}\text { Warm Air } \\
\text { (Water) }\end{array}$ & $24^{\circ} \mathrm{C}$ & $25^{\circ} \mathrm{C}$ & $25^{\circ} \mathrm{C}$ & $26^{\circ} \mathrm{C}$ & $26^{\circ} \mathrm{C}$ & $25^{\circ} \mathrm{C}$ \\
\hline $\begin{array}{c}\text { Hot Air } \\
\text { (Alcohol } \\
\text { Lamp) }\end{array}$ & $29^{\circ} \mathrm{C}$ & $30^{\circ} \mathrm{C}$ & $31^{\circ} \mathrm{C}$ & $30^{\circ} \mathrm{C}$ & $30^{\circ} \mathrm{C}$ & $30^{\circ} \mathrm{C}$ \\
\hline
\end{tabular}

The temperature sensor was tested, and the results are shown in Table 1. The following compounds were utilized in the tests: iced, water, and an alcohol lamp. For the temperature sensor's initial test, an ice substance was employed to simulate cold Air. The first test resulted in a mean temperature of 13.6 ${ }^{\circ} \mathrm{C}$. Warm Air was employed as the test substance for the temperature sensor's second test. The second test resulted in a mean temperature of $25.2^{\circ} \mathrm{C}$. Finally, for the final test, an Alcohol Lamp was utilized to generate hot Air. The mean of the most recent test was $30.0^{\circ} \mathrm{C}$.

According to the US Metric Association (USMA), temperatures below 20 degrees are considered cold, those between 20 and 27 degrees are considered moderate, and those above 27 degrees are considered hot. The Temperature sensor's readings will be supplied to the Application. The results of the temperature readings are supported by the study which observed that the temperature readings from the following samples were $13.6^{\circ} \mathrm{C}$ for Cold Air, $25.6^{\circ} \mathrm{C}$ for Warm Air, and $30.8^{\circ} \mathrm{C}$ for Hot Air based on the results of the study conducted [8], which was closely related to the current findings of these experimental results.

Table 2: Soil Moisture Sensor Reading

\begin{tabular}{|c|c|c|c|c|c|c|}
\hline Condition & Trial 1 & $\begin{array}{c}\text { Trial } \\
2\end{array}$ & $\begin{array}{c}\text { Trial } \\
3\end{array}$ & $\begin{array}{c}\text { Trial } \\
4\end{array}$ & $\begin{array}{c}\text { Trial } \\
5\end{array}$ & Mean \\
\hline Dry Soil & 1023 & 1022 & 1023 & 1023 & 1020 & 1022.2 \\
\hline Wet Soil & 457 & 481 & 526 & 478 & 570 & 502.4 \\
\hline
\end{tabular}

The analog values for testing the Soil Moisture sensor are shown in Table 2. Dry dirt was employed in the first condition test. The measurements were constant; the first test resulted in a mean of 1022.2. Wet soil was employed in the second condition test. The values of the readings fluctuate throughout time; the mean of the Wet soil sample test was 502.4.

Table 3: Soil Moisture Reading on the Application

\begin{tabular}{|c|c|c|c|c|c|}
\hline Condition & Trial 1 & Trial 2 & Trial 3 & Trial 4 & Trial 5 \\
\hline Dry Soil & LOW & LOW & LOW & LOW & LOW \\
\hline Wet Soil & HIGH & HIGH & HIGH & HIGH & HIGH \\
\hline
\end{tabular}

The Soil Moisture sensor's capability was demonstrated in Table 3. Dry dirt was employed in the initial test. The results were consistent between trials 1 and 5, indicating that the soil moisture level was LOW. Wet soil was employed in the second test. The results were consistent from trial 1 to trial 5, indicating that the soil was quite moist. It was coded so that if the soil moisture sensor's readings are 700 or greater, the application will display LOW soil moisture; if the readings are less than 700, the application will display HIGH soil moisture. 
ISSN (online): 2581-3048

Volume 5, Issue 11, pp 44-51, November-2021

https://doi.org/10.47001/IRJIET/2021.511008

Table 4: Ultrasonic Sensor Reading

\begin{tabular}{|c|c|c|c|c|c|c|}
\hline Condition & Trial 1 & Trial 2 & Trial 3 & Trial 4 & Trial 5 & Mean \\
\hline $\begin{array}{c}10 \mathrm{~cm} \\
\text { (Ruler) }\end{array}$ & $9 \mathrm{~cm}$ & $10 \mathrm{~cm}$ & $10 \mathrm{~cm}$ & $11 \mathrm{~cm}$ & $10 \mathrm{~cm}$ & $\begin{array}{c}10.0 \\
\mathrm{~cm}\end{array}$ \\
\hline $\begin{array}{c}30 \mathrm{~cm} \\
\text { (Ruler) }\end{array}$ & $30 \mathrm{~cm}$ & $30 \mathrm{~cm}$ & $29 \mathrm{~cm}$ & $28 \mathrm{~cm}$ & $30 \mathrm{~cm}$ & $\begin{array}{c}29.4 \\
\mathrm{~cm}\end{array}$ \\
\hline
\end{tabular}

Table 4 showed the Ultrasonic sensor's digital readings. The first test employed a 10 centimeter by a ruler. The readings ranged from $9 \mathrm{~cm}$ to $11 \mathrm{~cm}$. The first test resulted in a mean of $10.0 \mathrm{~cm}$. In the second test, a ruler 30 centimeters long was employed. The second test results were likewise relatively consistent, ranging between $28 \mathrm{~cm}$ and $30 \mathrm{~cm}$. The second test resulted in a mean of $29.4 \mathrm{~cm}$.

Table 5: Ultrasonic Functionality Test on the Irrigation System

\begin{tabular}{|c|c|c|c|c|c|}
\hline Ultrasonic Sensor & \multicolumn{5}{|c|}{ Water pump and Servo motor Condition } \\
\cline { 2 - 6 } Reading & Trial 1 & Trial 2 & Trial 3 & Trial 4 & Trial 5 \\
\hline $1 \mathrm{~cm}$ (Full) & OFF & OFF & OFF & OFF & OFF \\
\hline $8 \mathrm{~cm}$ (Half Full) & OFF & OFF & OFF & OFF & OFF \\
\hline $16 \mathrm{~cm}$ (Empty) & ON & ON & ON & ON & ON \\
\hline
\end{tabular}

Table 5 demonstrated the Ultrasonic sensor's functionality in conjunction with the irrigation system. The ultrasonic sensor was positioned directly above the water reservoir. The first test used a full water reservoir and an ultrasonic sensor reading of 1 centimeter. The findings of trials 1 to 5 were consistent, indicating that the water pump and servo motor should be turned off. The second test used a half-full water reservoir and an ultrasonic sensor reading of 8 centimeters. The findings of the second test from trials 1 to 5 were also consistent, indicating that the water pump and servo motor should be turned off. The water reservoir was depleted during the last test, and the ultrasonic sensor registered a value of 16 centimeters. The third test from trials 1 through 5 was consistent but resulted in the water pump and servo motor turning on. It was programmed that if the Ultrasonic sensor reads 15 centimeters or greater, the water pump and servo motor will activate. As a result, if the reading falls below two centimeters, the water pump and servo motor will shut down. The Ultrasonic sensor's function is to determine the water level within the water reservoir. This capability enabled the project to have an irrigation system with an automated fertilizer and water mixer.

\section{CONCLUSIONS}

The prototype and applications developed for the Internet of Things-based Automated Garden Irrigation and Monitoring System using Advanced Technology were highly reliable and beneficial for modern gardening. The results indicated that all hardware components, including sensors and a microcontroller, functioned effectively, as observed in a series of experimental trials. In contrast, software components developed for this project, including Google firebase and a mobile application, worked properly by sending commands and receiving data from the project, as observed in a series of experimental trials conducted by the researchers. Thus, the Internet of Things-based Automated Garden Irrigation and Monitoring System using Advanced Technology was reliable and relevant to modern gardening.

\section{RECOMMENDATIONS}

The researcher suggested the following for the project's future:

1. Future scholars should adopt and continue this study to better develop its system.

2. Add more monitoring components like LCD and camera system.

3. Install a switch or other alternative control for the irrigation system.

4. A solar panel and a battery should be used to keep the system running in case of a power loss.

5. It is advised to include more temperature-controlling hardware components such as fans.

6. More Arduino research projects should be explored for future research applications.

\section{ACKNOWLEDGEMENT}

The researchers are grateful and thankful to the school principal for enabling them to conduct this study and for providing assistance for all of the necessary resources that the authors required for this project.

\section{REFERENCES}

[1] P. Lapada, L. Simpal, and A. Jurao,"Simplified Arduino Based Smart Home Monitoring System for Effective Gardening." unpublished.

[2] A.N. Yumang, A.C. Paglinawan, L.A. A. Perez, J.F.F. Fidelino, \& J.B.C Santos. (2017, April).Soil infiltration rate as a parameter for soil moisture and temperature based Irrigation System.6th IEEE International Conference on Control System, Computing and Engineering (ICCSCE), pp. 286-291.doi: 10.1109/ICCSCE.2016.7893586.

[3] G. Cid, T. Lopez, F. Gonz ' alez, J. Herrera, and M.E. Ruiz. (2011).Propiedades' f'isicas de algunos suelos de Cuba y su uso en modelos de simulacion.' Revista Ciencias Tecnicas Agropecuarias, scielocu, Vol. 20, [2] pp. 42 - 46.

[4] J.E. Gomez,F.R. Marcillo, F.L. Triana, V.T. Gallo, B.W. Oviedo, and V.L. Hernandez. (2017, June). IoT for Environmental Variables Urban Areas. Procedia 
ISSN (online): 2581-3048

Computer Science, 2017, 109, pp. $67 \quad-$ 74.doi.org/10.1016/j.procs.2017.05.296

[5] G. Santucci, and S. Lange (2008, September 5).Internet of Things in 2020: A roadmap for the future. 2008, European Commission DG Infso \& European Technology Platform on Smart Systems Integration. pp. 1-32.https://docbox.etsi.org

[6] R. Venkatesan, and A. Tamilvanan. (2018, February). A sustainable agricultural system using IoT. International Conference on Communication and Signal Processing (ICCSP). doi: 10.1109/ICCSP.2017.8286464

[7] G. Arvind, V. Athira, H. Haripriya, R. Rani, and S. Aravind. (2018, February). Automated irrigation with advanced seed germination and pest control. IEEE Technological Innovations in ICT for Agriculture and Rural Development (TIAR), pp. 64-67, doi: 10.1109/TIAR.2017.8273687.

[8] M. Simpal, A. Mangakoy, A. Jurao, S.Mancenero, and C. Namol. (2021, January). Arduino Based Auto Monitoring and Controlling System with Gsm Module Integration for the Optimal Growth of Mushroom (Pleurotus Djamor). 7(1). pp. 81-90.

[9] G. Carrion, B. Barzallo, and M. Huerta. (2018, September).Monitoring and irrigation of an urban garden using IoT. IEEE Colombian Conference on Communications and Computing (COLCOM), pp. 1-6, doi: 10.1109/ColComCon.2018.8466722.

[10] Verdouw, C., Tekinerdogan, B. and Wolfert S. (2016, December).Internet of Things in agriculture. Perspectives in Agriculture, Veterinary Science, Nutrition and Natural Resources. doi: 10.1079/PAVSNNR201611035.

[11] R. Gunawan,I. Taufik, and E. Mulyana. (2020, February). Chatbot Application on Internet of Things (IoT) to Support Smart Urban Agriculture. IEEE 5th International Conference on Wireless and Telematics (ICWT), pp. 1-6, doi: 10.1109/ICWT47785.2019.8978223.

[12] Z. Ahmad,M. Pasha,A. Ahmad, A. Muhammad,S. Masud,M. Schappacher, and A. Sikora. (2017, November).Performance evaluation of IEEE 802.15.4compliant smart water meters for automating large-scale waterways." 9th IEEE International Conference on Intelligent Data Acquisition and Advanced Computing Systems: Technology and Applications (IDAACS), pp. 746-751, doi: 10.1109/IDAACS.2017.8095189.

[13] R. Dolci. (2017, September). IoT Solutions for Precision Farming and Food Manufacturing: Artificial Intelligence Applications in Digital Food. IEEE 41st Annual Computer Software and Applications Conference (COMPSAC), pp. 384-385, doi: 10.1109/COMPSAC.2017.157.
[14] V. Gokul, and S. Tadepalli. (2017, September). Implementation of smart infrastructure and noninvasive wearable for real time tracking and early identification of diseases in cattle farming using IoT. International Conference on ISMAC (IoT in Social, Mobile, Analytics and Cloud) (I-SMAC), pp. 469-476).Doi: 10.1109 / ISMAC.2017.8058394.

[15] C. Yoon,M. Huh, S. Kang, J. Park, and C. Lee. (2018, March).Implement smart farm with IoT technology. 20th International Conference on Advanced Communication Technology (ICACT), pp. 749-752, doi: 10.23919/ICACT.2018.8323908.

[16] S. Ruengittinun, S. Phongsamsuan, and P. Sureeratanakorn. (2017, October). Applied internet of thing for smart hydroponic farming ecosystem (HFE). 10th International Conference on Ubi-media Computing and Workshops (Ubi-Media), pp. 1-4, doi: 10.1109/UMEDIA.2017.8074148.

[17] P. Tanmayee. (2017, October).Rice crop monitoring system-A lot based machine vision approach. International Conference on Nextgen Electronic Technologies: Silicon to Software (ICNETS2), pp. 26-29, doi: 10.1109/ICNETS2.2017.8067890.

[18] A.Rau, J. Sankar,A. Mohan,D. Das Krishna, and J. Mathew. (2017, October). IoT based smart irrigation system and nutrient detection with disease analysis. IEEE Region 10 Symposium (TENSYMP), pp. 1-4, doi: 10.1109/TENCONSpring.2017.8070100.

[19] R. Maia,I. Netto, and A. Tran. (2017, December). Precision agriculture using remote monitoring systems in Brazil. IEEE Global Humanitarian Technology Conference (GHTC), pp. 1-6, doi: 10.1109/GHTC.2017.8239290.

\section{AUTHORS BIOGRAPHY}

Mohamad Simpal, Science, Technology, Engineering, and Mathematics Department, Esperanza National High School, Philippines. Master Teacher I.simpalmohamad1989@gmail.com

Aldrin Jurao, Jr, Science, Technology, Engineering, and Mathematics Department, Esperanza National High School, Philippines. BS Mechanical Engineering.

Cydrick John Estrella, Science, Technology, Engineering, and Mathematics Department, Esperanza National High School, Philippines. BS Business Administration.

Karyl June Jardiolin, Science, Technology, Engineering, and Mathematics Department, Esperanza National High School, Philippines. BS Marine Engineering. 
Trisha Claire Leyza, Science, Technology, Engineering, and Mathematics Department, Esperanza National High School, Philippines. BS Medical Technology.

\section{Citation of this Article:}

Mohamad Simpal, Aldrin Jurao, Jr., Cydrick John Estrella, Karyl June Jardiolin, Trishia Claire Leyza, "IoT-Based Automated Garden Irrigation and Monitoring System Using Advanced Technology" Published in International Research Journal of Innovations in Engineering and Technology - IRJIET, Volume 5, Issue 11, pp 44-51, November 2021. Article DOI https://doi.org/10.47001/IRJIET/2021.511008 